\title{
A INFLUÊNCIA DO SOM NA PERCEPÇÃO E APROPRIAÇÃO DO ESPAÇO PELO CEGO
}

\author{
AZEVEDO, Beatriz \\ Universidade Federal do Rio Grande do Norte, e-mail: beatrizsbazevedo@hotmaill.com \\ CASTRO, Sílvia \\ Universidade Federal do Rio Grande do Norte, e-mail: ribeirosilviah@gmail.com
}

\begin{abstract}
RESUMO
Com enfoque na promoção da arquitetura acessível, desenvolveu-se um estudo, dentro do quadro de uma disciplina de graduação, para identificar aspectos fundamentais na percepção do ambiente pelas pessoas com deficiência visual. O objetivo principal convergiu para a compreensão da influência do som na apropriação do espaço público pelo cego, incrementando a discussão acerca do papel do arquiteto e urbanista na produção de ambientes inclusivos. Para tanto, utilizou-se de entrevistas semiestruturadas, mapeamento comportamental, medições acústicas e simulação em estúdio. Dessa forma, pode-se observar, por tendência, menor tolerância das pessoas sem visão ao nível de pressão sonora, estando diretamente relacionada a sua presença em determinados espaços e ao seu desconforto mental. As análises apontaram para diretrizes de projeto que vislumbram a inclusão social e estimulam a permanência em ambientes coletivos.
\end{abstract}

Palavras-chave: Deficiência visual; Arquitetura inclusiva; Acústica urbana.

\begin{abstract}
With a focus on the promotion of accessible architecture, a study was developed within the framework of a graduation discipline to identify fundamental aspects in the perception of the environment by the visually impaired. The main objective was to understand the influence of sound in the appropriation of the public space by the blind, increasing the discussion about the role of the architect and urbanist in the production of inclusive environments. For that, we used semistructured interviews, behavioral mapping, acoustic measurements and simulation in the studio. Thus, we can observe, by tendency, lower tolerance of people without vision at the level of sound pressure, being directly related to their presence in certain spaces and to their mental discomfort. The analyzes pointed to project guidelines that envisage social inclusion and stimulate permanence in collective environments.
\end{abstract}

Keywords: Visual deficiency; Inclusion archltecture; Urban acoustics.

\section{INTRODUÇÃO}

Dentro da amplitude das abordagens que Arquitetura e Urbanismo contempla, a acessibilidade é um tema recente. Os estudos na área ainda são eminentes e sua escassez culmina na reprodução de propostas arquitetônicas pouco ou não inclusivas, restringindo-se, na maioria dos casos, ao mero cumprimento das legislações incidentes. Nisto, também se insere os espaços públicos, vistos como verdadeiro palco de interação e comunicação entre distintos, lugar da vida

AZEVEDO, B.; CASTRO, S. A influência do som na percepção e apropriação do espaço pelo cego. In: SIMPÓSIO BRASILEIRO DE QUALIDADE DO PROJETO NO AMBIENTE CONSTRUÍDO, 6., 2019, Uberlândia. Anais... Uberlândia: PPGAU/FAUeD/UFU, 2019. p. 842-852. DOI https://doi.org/10.14393/sbqp19078. 
coletiva. A não adequação destes, portanto, resulta na exclusão dos processos de ocupação da cidade.

Abre-se um leque de questões a serem investigadas, proporcionais à complexidade do assunto. Este trabalho direciona suas análises aos aspectos subjetivos que envolvem participação dos cegos na vida pública por meio da sua permanência em espaços livres. Neste aspecto, o sentido auditivo da pessoa com deficiência visual e a particularidade da sua percepção da paisagem sonora emergem como objeto do estudo, entendendo que, depois do ver, o ouvir é o sentido que mais permite a caracterização de um espaço. Nessa perspectiva, a escolha pelo tema almeja não só contribuir para a produção de espaços mais inclusivos, mas também despertar novos olhares e interesses na questão, não encerrando a discussão, mas fomentando-a.

Objetiva-se, de forma geral, compreender a influência da qualidade sonora na apropriação do espaço público pelo cego, a fim de incrementar a discussão acerca do papel do Arquiteto e Urbanista na produção de espaços inclusivos. Para tanto, busca-se entender os aspectos quantitativos e qualitativos na identificação da paisagem sonora pelo cego; identificar a tendência de ocupação dos espaços públicos pela pessoa com deficiência visual no universo de estudo; analisar os aspectos sonoros relacionados ao uso e permanência dos cegos nos espaços públicos e; contribuir e apontar diretrizes projetuais para a proposição de espaços sensoriais e inclusivos, fomentando a conscientização e o despertar do profissional acerca da responsabilidade na produção de espaços de uso coletivo.

\section{O CEGO E O AMBIENTE: PERCEPÇÃO, PAISAGEM SONORA E APROPRIAÇÃO}

Besse (2014) defende a paisagem como sendo o espaço experimentado pelos sentidos humanos, tratando-se, portanto, do "encontro concreto entre o homem e o mundo que o cerca", dado das mais variadas maneiras.

Ao comparar o uso dos cinco sentidos, avalia-se juntamente às discussões de Valentini (2012), que a cultura atual vislumbra a construção de uma hegemonia da visão, intensificada pela multiplicidade de invenções tecnológicas que privilegia o uso da imagem em detrimento das demais formas de apreensão, sobretudo na produção da arquitetura.

Ressalta-se que, de acordo com a Organização Mundial de Saúde (OMS), há dois níveis de cegueira: baixa visão - sendo esta leve ou moderada, quando é possível enxergar em determinadas distâncias com o auxilio de ferramentas ópticas; ou profunda, quando é possível apenas captar luzes e sombras - e a cegueira total, quando não há quaisquer resíduos visuais, podendo ser cegueira congênita - quando se nasce sem o uso desse sentido - ou adquirida durante a vida.

Para a pessoa com deficiência visual completa, seu processo cognitivo de apreensão do espaço se dará pela intensificação do uso dos demais sentidos ao excetuar-se a visão. Valentini (2012) destaca que, para as pessoas cegas, "o 'perceber' é o resultado de muita sensibilidade e do treinamento de orientação de mobilidade" (VALENTINI, 2012, p.91). Devem ser treinadas para reconhecer 0 que a autora denomina de "pistas de orientação" (VALENTINI, 2012, p. 86), servindo-se da sombra sonora, da ecolocalização e da memória cinética para compreensão e locomoção. A respeito de sombra sonora, a autora compara a 
produzida por um objeto ao receber raios de luz que, se tratando do som, produz não uma região escura, mas de silêncio, sendo possível prever a localização de objetos e barreiras, e a direção da produção sonora. A ecolocalização se trata da emissão de sons para averiguar dimensões por meio da sua reflexão e reverberação em paredes, tetos e matérias. Além destes, a lembrança motora se aplica em deslocamentos já conhecidos, sem a necessidade de processar movimentos e distâncias.

De tal modo, Valentini (2012) defende o uso da audição, para o cego, como a principal ferramenta de percepção da profundidade do ambiente por meio da captação da paisagem sonora. Esse termo, utilizado pelo músico Murray Schafer em 1997, remete ao conjunto de sons agradáveis e desagradáveis, perceptíveis ou ignorados presentes no espaço observado. De acordo com Hirashima (2014), os principais parâmetros para a sua descrição remetem à variação da amplitude do som e à constância dos eventos sonoros, preferindose baixas pressões e episódios constantes.

Cavalcante e Elali (2012) concluem que, à medida que a pessoa interioriza o espaço, se projeta neste por meio da apropriação, que é a resultante física e acional do processo cognitivo do ambiente, ou seja, a reação da análise pessoal do conteúdo recebido pelos sentidos, culminando na determinação de um lugar seu (CAVALCANTE; ELALI, 2012). Sabendo que o grau mínimo de apropriação se dá pela compreensão do ambiente, o qual suscita o sentimento de domínio e familiaridade (CAVALCANTE; ELALI, 2012), no contexto da deficiência visual, a percepção da paisagem sonora torna-se artifício inicial neste processo. A adequação do espaço é vista, então, como forma de garantir ao cego a participação na formação da cidade.

Essa afirmação direciona à aplicação da Arquitetura Sensorial no contexto urbano em projetos que vislumbrem o estímulo de todos os sentidos, possibilitando sua leitura por meios além da visão.

\section{METODOLOGIA}

Foi elaborado um roteiro para compor uma entrevista semi-estruturada, com questões de ordem pessoal, para formar o perfil do entrevistado; questões acerca das lembranças sobre o local de estudo, como os sons frequentemente percebidos; e questões sobre a percepção do entrevistado no local, questionando, por exemplo, a localização do som que ouvia. As entrevistas foram realizadas na Escola de Música da Universidade Federal do Rio Grande do Norte (EMUFRN), com três cegos e um vidente (entrevistou-se o vidente para comparar seus resultados com os dos cegos). Posteriormente, foram entrevistados três cegos na parada de ônibus próxima à EMUFRN.

Foi realizado, ainda, o Mapeamento Comportamental, metodologia de Sommer \& Sommer (1980), que consiste numa observação do espaço e dos seus usuários (PINHEIRO; ELALI; FERNANDES, 2008). De acordo com Sommer \& Sommer (1980), há duas variáveis desse método. No mapeamento centrado no lugar, o foco é o espaço, que é dividido em setores (Figura 1) e são indicadas as atividades ali realizadas. Já no mapeamento centrado na pessoa, observa-se os trajetos e as atividades realizadas pelos usuários. Ressalta-se que a aplicação do procedimento abrangeu os minutos que antecederam uma aula com pessoas com deficiência visual. 


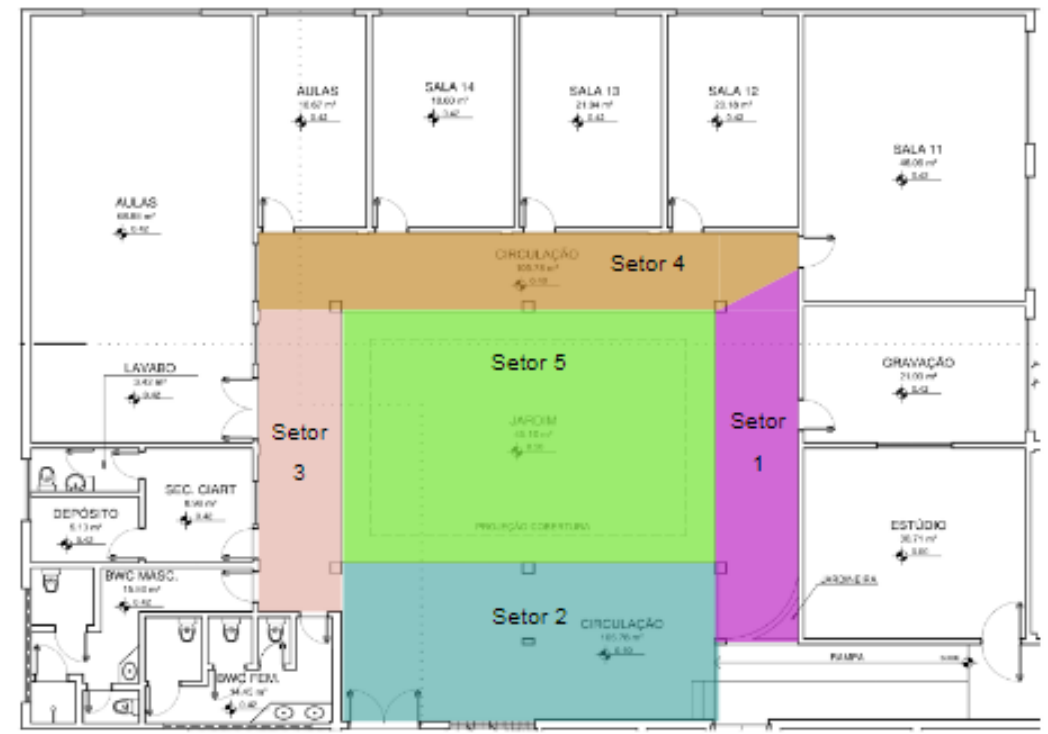

Figura 1 - Setores do pátio -

Fonte: Superintendência de Infraestrutura - UFRN (2018), modificado pelas autoras (2018)

Visando caracterizar a paisagem sonora do local, realizou-se medições acústicas baseadas na NBR 10151 (ABNT, 2000) antes e após as entrevistas (a forma de representar tais dados encontra-se na tabela e na figura abaixo) e 0 mapeamento comportamental. Além disso, durante o mapeamento, as medições foram realizadas a cada 5 minutos, durante um minuto. $O$ mesmo tempo foi utilizado nas medições na parada de ônibus.

\section{Tabela 1 - Escala cromática de verificação do nível de pressão sonora}

\begin{tabular}{|c|c|}
\hline Intervalo (dB) & Cor correspondente \\
\hline $48.0-51.9$ & \\
\hline $52.0-55.9$ & \\
\hline $56.0-59.9$ & \\
\hline $60.0-63.9$ & \\
\hline $64.0-67.9$ & \\
\hline $68.0-71.9$ & \\
\hline $72.0-75.9$ & \\
\hline
\end{tabular}

Fonte: Autoras (2018)

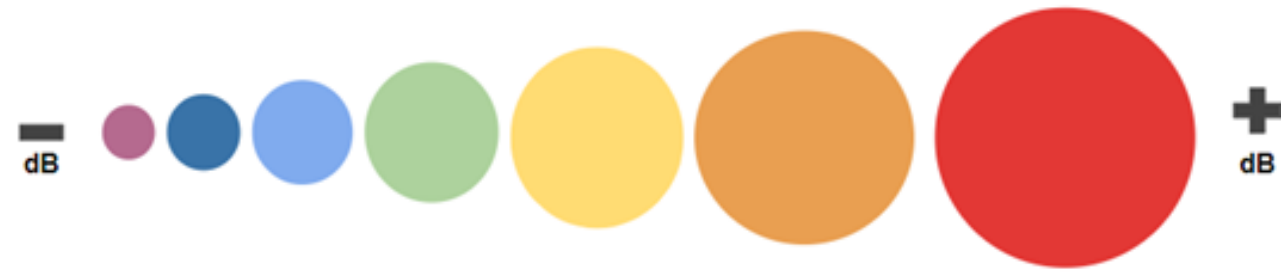

Figura 2 - Escala gradativa de nível de pressão sonora -

Fonte: Autoras (2018) 
A simulação em estúdio ocorreu na EMUFRN. Os 2 cegos e o vidente entrevistados participaram de um teste sonoro com três tipos de som: ruído rosa (todas as frequências audíveis pelo ser humano); música instrumental (Perfect, do artista Ed Sheeran, interpretada por Brooklyn Duo), escolhida por ser considerada agradável pelas pesquisadoras e; ruído urbano (áudio com ruídos de veículos). O volume do aparelho de reprodução sonora era aumentado gradativamente e os entrevistados sinalizaram para as pesquisadoras quando se sentiram desconfortáveis e quando não toleraram mais. Além disso, o nível de pressão sonora do ambiente foi medido durante toda a simulação.

\section{RESULTADOS}

\section{1 "Eu", espaço e o som}

Nesta etapa, buscou-se depreender a importância da audição para a compreensão, localização e locomoção no espaço, adentrando em questões de acessibilidade levantados pelos entrevistados. Identificou-se a preferência por sons naturais e calmos, tanto para os cegos, quanto para o vidente. Entretanto, para os sem visão, correlaciona-se ainda à apreciação do espaço, o qual explica João':

Assim, quando a gente gosta de alguma coisa que tranquiliza a gente, você fica bem atento aquele som, você se admira com o que você ouve. Para a gente, a gente 'tá' enxergando a natureza - se for som da natureza - daquela forma, já que a gente não 'tá' vendo.

Outro tipo pontuado refere-se ao "som do silêncio" o qual permite maior relaxamento devido à ausência de informações constantes a serem processadas. Como exemplo disto, apresentam o estúdio de música da EMUFRN quando não há ensaio, onde a presença do isolamento acústico possibilita a audição da própria respiração.

No ambiente urbano, contudo, verificou-se uma dualidade: os ruídos são desconfortáveis e chegam a causar confusão cognitiva, mas também são vistos como necessários para indicar o sentido do fluxo, dimensão de ruas e localização de cruzamentos. Já em ambientes abertos e livres não é possível o uso referencial de fontes sonoras, visto serem dissipadas no espaço e não suficientes, sendo preciso outros artifícios para $\circ$ deslocamento e reconhecimento espacial.

Quanto a percepção do som em ambientes internos, destacaram estratégias, como o uso da sombra sonora e da ecolocalização por meio do grito, do bater das palmas e da bengala ou do estalar de dedos. Nesta perspectiva, enfatizaram o mapeamento imediato das fontes sonoras, ao adentrar em espaços fechados, para de facilitar seus movimentos no local, sobretudo no reconhecimento da saída. Desse modo, em situações de barulho, sobretudo ruídos intermitentes e agudos, o recinto torna-se intolerável, culminando em impaciência e desorientação, ao que esclarece Silvano:

I Os entrevistados possuem nome fictício. 
Na hora que chega um ruído acima do normal aqui, é como se a gente ficasse cego de novo. A gente perde aquela noção do que tá acontecendo ao nosso redor.

Assim, concluíram que a paisagem sonora ideal corresponderia àquela em que houvesse baixos níveis de pressão sonora e maior distinguibilidade das fontes. Em oposição a isso, afirmaram que evitam alguns lugares de uso coletivo devido ao ruído, como shopping centers A ausência de mapeamentos e elementos de referência também foram citados como fatores relevantes, sendo necessário um acompanhante para guiá-los. A presença do piso tátil foi questionada pelos entrevistados sem visão, criticando o uso equivocado do piso de alerta, sugerindo a criação de um outro para a mudança de sentido ou existência de rampas e escadas. Para eles, a sinalização tátil de piso não confere segurança no deslocamento em locais grandes e abertos, sendo utilizado apenas após um reconhecimento do espaço.

Não houve indicação alguma do vidente quanto o uso do som para locomoção ou percepção do espaço. Relatou não evitar nenhum lugar devido ao ruído ou dificuldade em lidar com sons urbanos, embora corrobore com o incômodo proveniente destes.

Tabela 2 - Grau de desconforto e insuportabilidade do som pelos entrevistados

\begin{tabular}{|c|c|c|c|c|c|c|}
\hline \multirow{2}{*}{ Tipos de sons } & \multicolumn{6}{|c|}{ Níveis de intolerância ao tipo de som (dB) } \\
\cline { 2 - 8 } & \multicolumn{2}{|c|}{ Vidente } & \multicolumn{2}{c|}{ Silvano } & \multicolumn{2}{c|}{ João } \\
\cline { 2 - 7 } & $\begin{array}{c}\text { Descon- } \\
\text { forto }\end{array}$ & $\begin{array}{c}\text { Insupor- } \\
\text { tável }\end{array}$ & $\begin{array}{c}\text { Desco- } \\
\text { forto }\end{array}$ & $\begin{array}{c}\text { Insupor- } \\
\text { rtável }\end{array}$ & $\begin{array}{c}\text { Descon- } \\
\text { forto }\end{array}$ & $\begin{array}{c}\text { Insupor- } \\
\text { tável }\end{array}$ \\
\hline Ruído rosa & 74 & 97.7 & 80 & 90 & 76 & 81 \\
\hline $\begin{array}{c}\text { Música } \\
\text { Instrumental }\end{array}$ & 95 & 105.9 & 84 & 100 & 106 & 108 \\
\hline $\begin{array}{c}\text { Ruído } \\
\text { urbano }\end{array}$ & 94 & 105 & 85 & 95 & 91 & 98 \\
\hline
\end{tabular}

Fonte: Elaborado pelas autoras a partir do teste acústico em estúdio da Escola de Música, 2018.

Assim, com a perceptível divergência na suportabilidade do som e suas fontes, buscou-se realizar um teste em estúdio para melhor precisar o grau de desconforto e tolerância ao nível de pressão sonora para o ruído rosa, de tráfego urbano e em melodia instrumental, estando os dados expostos na Tabela 2. Entretanto, ressalta-se possível margem de erro, aqui não mensurada, devido experiência sob condições controladas, sem a influência de um contexto paisagístico real.

Esse método possibilitou a complementação da análise in loco, sugerindo, além do limite de pressão sonora, os aspectos de amplitude, tipo e quantidade de fontes. Desta, ressalta-se que não houve grandes variações no nível de desconforto entre os sem e com visão, diferindo apenas no grau de insuportabilidade, reservando o maior alcance para o vidente. Houve ainda 
uma tolerância comum para o som instrumental, estando próximos ao limiar da dor ${ }^{2}$, sendo visto como um som agradável.

Pode-se inferir também que a amplitude entre o nível de desconforto e a insuportabilidade do som, para os cegos, foi bem menor, chegando ao máximo de $10 \mathrm{~dB}$ frente aos $23,7 \mathrm{~dB}$ do vidente. Observou-se ainda uma maior flexibilidade ao ruído urbano, corroborando com a adaptação psicológica da paisagem sonora cotidiana indicada por Hirashima (2014). Por fim, presume-se, por tendência, uma menor anvência aos ruídos por parte dos cegos, sendo $7 \mathrm{~dB}$ inferiores aos com visão em insuportabilidade.

\subsection{Percepção do lugar}

A entrevista no pátio da EMUFRN contou com a presença de crianças e professores próximos aos pontos 03 e 04 (Figura 3), conversando, lanchando e jogando bola; sons de ensaio de violoncelo provinham da sala 14, próxima ao ponto 02 e, no 01, dois adultos conversavam (Figura 3). Salienta-se que os entrevistados localizavam-se em " $x$ ". Esses fatos repercutiram diretamente nos valores verificados no decibelímetro, que demonstrou maior intensidade sonora nos pontos 02,03 e 04 .

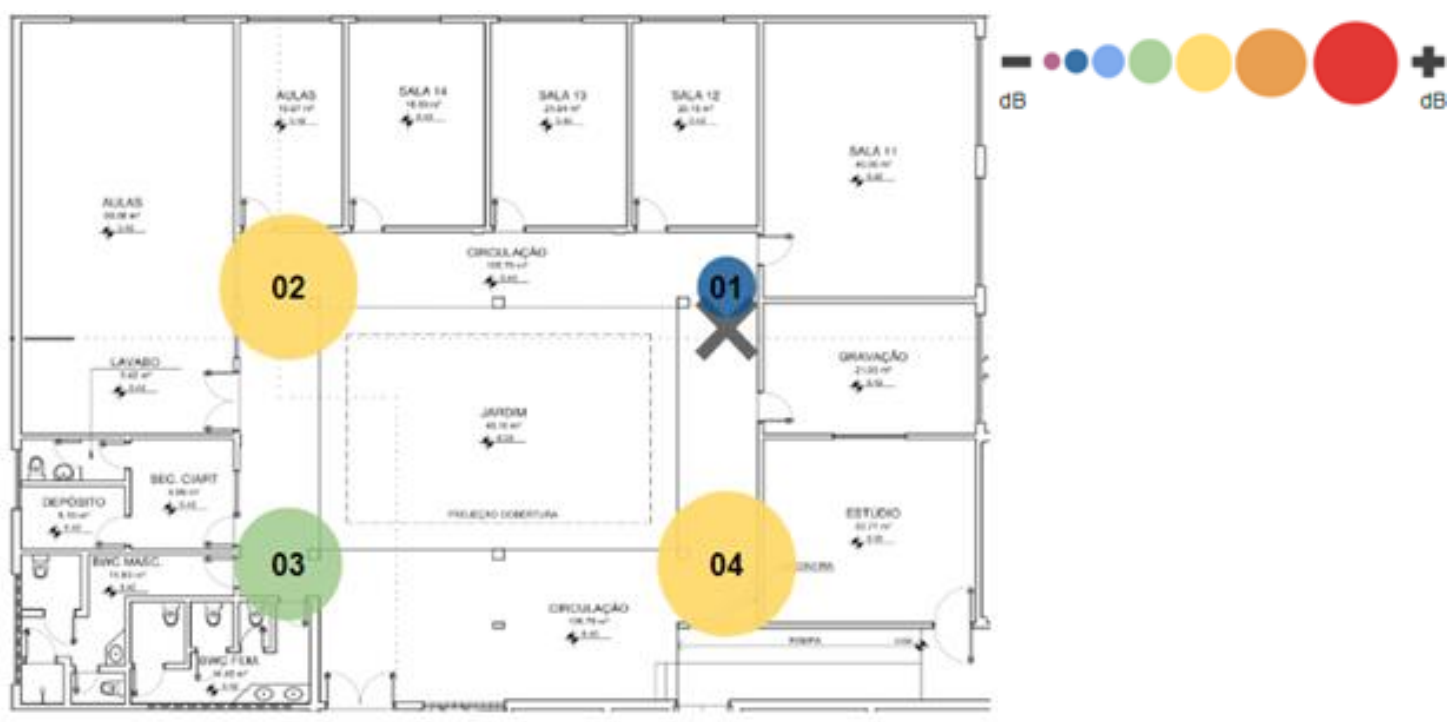

Figura 3 - Espacialização do nível de pressão sonora no pátio -

Fonte: Superintendência de Infraestrutura - UFRN (2018), modificado pelas autoras (2018)

Todos os entrevistados afirmaram estar bem (estado emocional), mas desconfortáveis com o ruído do ambiente. Quanto à avaliação do volume sonoro, relataram estar de mediano a alto, quando o nível de pressão sonora estava a uma média de 61.4dB.

Sobre a distinção, localização e indicação de movimento das fontes, todos apontaram-nas com precisão. Quanto ao som que mais chamou a atenção, indicaram o violoncelo, por ser um som agradável; também foi elegido como o som de maior qualidade do ambiente. Sobre o de menor percepção, elegeram a conversa dos adultos, pelo baixo volume da fala. $O$ de maior incômodo foi

\footnotetext{
2 Nível de pressão sonora, entre 110 e 130dB (SOUZA; ALMEIDA; BRAGAÇA, 2012), que marca início de estímulos dolorosos para o ouvinte, podendo acarretar em danos fisiológicos.
} 
dos professores e crianças, devido à simultaneidade e à variedade de informações auditivas. Neste momento, um dos entrevistados confidenciou: "se eu estivesse só, eu já teria procurado outro canto".

No final da entrevista, a paisagem sonora havia se modificado: as crianças haviam se retirado e adultos estavam no ponto 01, aguardando a aula. Com isto, as pesquisadoras perceberam a inquietude dos entrevistados, que necessitaram de ajuda para deixar o lugar, que já alcançava 75.2dB.

$\mathrm{Na}$ entrevista com o vidente, as principais fontes sonoras provinham de ensaio no auditório próximo ao ponto 04 e de diversas aulas próximas aos pontos 01 e 02 (Figura 4).

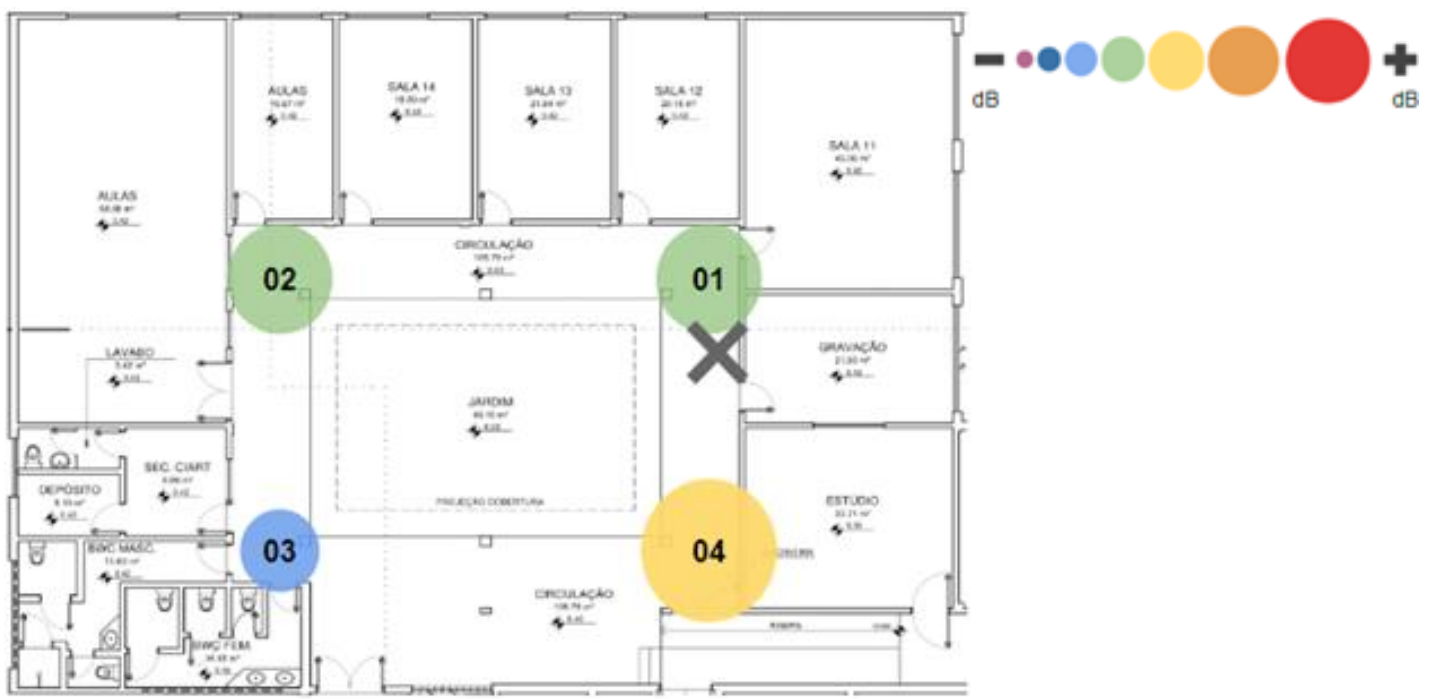

Figura 4 - Espacialização do nível de pressão sonora no pátio -

Fonte: Superintendência de Infraestrutura - UFRN (2018), modificado pelas autoras (2018)

O entrevistado, em bom estado emocional, indicou indiferença aos $63.3 \mathrm{~dB}$ e volume mediano, devido a facilidade de escuta da conversa. Distinguiu e localizou as fontes sonoras, estando atento a movimentos de portas e transeuntes. O som que mais chamou sua atenção originava-se do ensaio no auditório, devido a variação desarmoniosa e sua alta intensidade, adotando-o como o de maior incômodo. Quanto ao menos perceptível, apontou pelo balançar das folhas da árvore - som este não percebido pelas autoras e, aqui, atribuído à constante observância visual que o entrevistado manteve durante a entrevista: "o som da árvore, dá para perceber quando bate o vento... Tá vendo, ó?" (indica as folhas se movimentando lentamente). Adotou, ainda, o som da natureza como o mais agradável.

Com isso, observa-se que a faixa de incômodo levantada pelos entrevistados cegos (60 a 63.9dB) não correspondeu aos apontamentos do vidente que, a 63.3dB médios, classificou o som como "indiferente" em grau de desconforto, mesmo a principal fonte não ser bem avaliada pelo mesmo.

A outra fase do estudo ocorreu na parada de ônibus e restringiu-se aos cegos. Os valores máximos verificados devem-se à aproximação dos ônibus, alcançando $85.2 \mathrm{~dB}$. De modo geral, a média do ambiente correspondeu a $71.9 \mathrm{~dB}$, sendo de alta intensidade e desconforto para os depoentes, exceto 
para um deles que, ao compará-la a outras paradas e horários, considerou conforto acústico.

De tal modo, os três toleraram a paisagem, já que as características sonoras eram comuns para o ambiente urbano, causando, entretanto, tensão. Apontaram a sobreposição do ruído veicular constante, não possibilitando a identificação de outros sons com precisão. Em relação ao de maior incômodo, adotaram a aproximação do ônibus. Na ocasião, interrogou-os a respeito da tolerância maior entre sons intermitentes, contínuos e temporários, e concordaram na desvantagem de um barulho constante para o entendimento do espaço e seu deslocamento.

\subsection{Identificando a apropriação}

No Mapeamento Centrado no Lugar, obteve-se 61 registros de comportamento: 50 de atividade estática, 9 de deslocamento e 2 de atividade dinâmica. Logo, trata-se de um lugar de espera. Repartindo entre cego, baixa visão e vidente o comportamento mais realizado, tem-se que videntes aparecem mais nos registros (28), seguidos de cegos (14) e baixa visão (8). Isso mostra que, embora a aula esteja repleta de pessoas com deficiência visual, os videntes permaneceram no lugar por mais tempo. Compõem esse grupo pessoas que auxiliaram os deficientes visuais e outros visitantes.

Analisando a ocupação por setores, viu-se que o setor 4 foi o mais ocupado pelos visitantes no geral. Realçando os cegos nessa análise, constatou-se que o setor 3, que contém a sala em que os alunos teriam aula, foi o mais ocupado.

No Mapeamento centrado na pessoa, cinco usuários foram observados: dois cegos, duas pessoas com baixa visão e um vidente. Inferiu-se que o principal objetivo do uso do espaço foi a espera da aula. Nos intervalos, ocorreu interação entre os alunos. Percebeu-se que para os cegos e as pessoas com baixa visão que não fazem uso de bengalas, os movimentos realizados no espaço foram curtos e muito próximos ao destino final.

\section{O PAPEL DO ARQUITETO}

Diante do exposto, sugere-se medidas que arquitetos possam realizar para estimular a permanência de cegos num ambiente, tornando-a agradável e segura. Ressalta-se que as propostas abaixo não dizem respeito à função apenas do arquiteto, mas também de outros profissionais, de modo a alertá-los para a inclusão.

1. Criar paradas de ônibus fechadas, para produzir barreiras para o som, com indicadores sonoros para a chegada do ônibus;

2. Tratar acusticamente os espaços públicos, possibilitando a compreensão do ambiente pelo cego;

3. Instalar mapas táteis nos espaços públicos, para que o cego tenha contato com a rota acessível e dê suporte ao mapeamento mental;

4. Implementar aplicativos para smartphones que auxiliem pessoas com deficiência, mostrando, por exemplo, recursos de acessibilidade existentes num local; 
5. Fiscalizar os níveis de pressão sonora em ambientes públicos e veículos de propaganda;

6. Inserir atividades de esporte, cultura e lazer em espaços de uso público;

7. Estimular pesquisas para reduzir o ruído produzido por veículos no meio urbano.

\section{CONSIDERAÇÕES FINAIS}

Em síntese, do ponto de vista da qualidade sonora do ambiente, é possível depreender o desconforto a partir dos $60 \mathrm{~dB}$ e intolerância aos $75 \mathrm{~dB}$ para os cegos, culminando em desorientação espacial e impossibilidade de deslocamentos independentes. Vislumbra-se a coerência com o limite indicado pela NBR 10152 (ABNT, 1987) para circulações internas escolares, estabelecendo um limite entre 45 e $55 \mathrm{~dB}$. Já na verificação em contexto urbano, definiu-se 82.7dB como desconforto, estando também de acordo com o controle estabelecido pela NBR 10151 de $55 \mathrm{~dB}$ para áreas externas mistas com predominância de uso residencial.

Já por meio da observação comportamental, infere-se, por meio desta pesquisa, que o objetivo do uso determinará a sua localização e a amplitude de seus deslocamentos no espaço, estando sujeitos a movimentos curtos e próximos ao objeto de interesse. Todavia, não foi possível precisar a relação existente entre os elementos sonoros e a apropriação no espaço.

Determinou-se ainda a preferência pela distinguibilidade sonora, preferindo-se ambientes calmos e com menores pressões. Além disso, optaram por ruídos passageiros em detrimentos dos contínuos, responsáveis por estresse e inquietação. Destaca-se, por fim, a necessidade de adaptação de espaços abertos a fim de proporcionar a reverberação dos sons, favorecendo o uso de referenciais sonoros para deslocamento e leitura física do ambiente.

Em vista disto, este estudo identificou a tendência ao desestímulo do uso de espaços públicos pelos cegos devido ao ruído, sendo indissolúvel aos quesitos de acessibilidade. Vislumbra-se, assim, um cenário de possível e necessária atuação, carente de instrumentos e medidas que estimulem a inserção dos cegos no contexto urbano. Sendo assim, os arquitetos precisam orientar esforços para despertar novas leituras e sensações, levando a apreciação pessoal do ambiente construído.

A interpretação dos dados colhidos em campo, por sua vez, pouco permitiu concluir, evocando o viés da temática e o mister de desenvolvimento de metodologias de investigação. Contudo, não invalida a contribuição sistemática na discussão, provendo, além de conclusões pertinentes a gnose dessa realidade, encaminhamentos de ações mitigatórias. A exemplo disto, algumas providências de fácil aplicação foram propostas que, no que the concerne, perpassam o público focado neste estudo, representando melhoria para a vitalidade urbana e interação entre todos os cidadãos.

\section{REFERÊNCIAS}

ASSOCIAÇÃO BRASILEIRA DE NORMAS TÉCNICAS (ABNT). NBR 10151: Acústica: Avaliação do ruído em áreas habitadas, visando o conforto da comunidade Procedimento. Rio de Janeiro, 2000. 
NBR 10152: Níveis de ruído para conforto acústico. Rio de Janeiro, 2015.

NBR 9050: Acessibilidade a edificações, mobiliário, espaços e equipamentos urbanos. Rio de Janeiro, 1987.

BESSE, J. O gosto do mundo: exercícios de paisagem. Tradução Annie Cambe. Rio de Janeiro: Edverj, 2014.

CAVALCANTE, S.; ELALI, G. A. Temas básicos em Psicologia Ambiental. Petrópolis, Rio de Janeiro: Vozes, 2012.

HIRASHIMA, S. Q. S. Percepção sonora e térmica e avaliação do conforto em espaços urbanos abertos do município de Belo Horizonte - MG. Tese (Doutorado em Tecnologia da Arquitetura) - Faculdade de Arquitetura e Urbanismo da Universidade de São Paulo (FAUUSP), São Paulo, 2014.

PINHEIRO, J.; ELALI, G.; FERNANDES, O. Observando a interação pessoaambiente: vestígios ambientais e mapeamento comportamental. In: PINHEIRO, J.; GÜNTHER, H. (Org.). Métodos de pesquisa nos estudos pessoa-ambiente. São Paulo: Casa do Psicológo, 2008. p. 75-104.

SOUZA, L. C. L.; ALMEIDA, M. G.; BRAGANÇA, L. Bê-á-bá da acústica arquitetônica: ouvindo a Arquitetura. $4^{\mathrm{a}}$ Ed. São Carlos: EdUFSCar, 2012.

SOMMER, R.; SOMMER, B. Behavioral Mapping. In: SOMMER, R.; SOMMER, B. A Practical Guide to Behavioral Research, Tools and Techniques. New York: Oxford, 1980. Cap. 14. p. 160-169. Tradução de José Q. Pinheiro.

VALENTINI, S. M. R. Os sentidos da paisagem. Tese (Doutorado - Área de concentração: Paisagem e ambiente), FAUUSP. São Paulo, 2012. 